\title{
Implementing a Behavior Health Policy in the Secondary School
}

Jamie Nikander, DAT, LAT, ATC ${ }^{\text {; }}$ Lindsey E. Eberman, PhD, LAT, ATC2

IWest Olympia Sports Medicine, Olympia, WA; ${ }^{2}$ Indiana State University, Terre Haute, IN

\begin{abstract}
Site-specific policies and procedures outlining the available services and emergency action plan (EAP) is vital to any athletic training clinic. The purpose of the following document is to provide athletic trainers with a framework for the development and successful implementation of evidencebased policies and procedures to improve athletic training services at secondary schools. Using a behavioral health policy as an example, the challenges and barriers to the development and implementation of new policies at a secondary school will be discussed. Policy development was largely influenced by each of the individual stakeholders involved in the approval process including school administration, school nurses and counselors, as well as community organizations. As in any setting, challenges to implementation of the behavioral health policy in these schools did occur. Each secondary school or school district will have a different model for medical services that will inherently change the policy at each location. Athletic trainers must know the resources available to them on and offcampus, and develop policies and procedures dependent on these resources. For clinicians in any athletic training setting, it is important to review your current policy and procedure manual to determine where improvements can be made. These documents help ensure patients are being provided the best possible care and help protect athletic trainers legally.
\end{abstract}

\section{Key Phrases}

Policy and Procedure Development, Professional Standards, Secondary Schools Patient Population

\section{Correspondence}

Dr. Jamie Nikander, West Olympia Sports Medicine, 1620 Cooper Point Rd SW, Olympia, WA 98502.

E-mail: Jamie.nikander@providence.org

Twitter: @jnikanderATC

\section{Full Citation}

Nikander J, Eberman LE. Implementing a behavior health policy in the secondary school. Clin Pract Athl Train. 2018;1(1):21-29.

https://doi.org/10.31622/2018/0001.5

Submitted: May 8, 2018 Accepted: May 29, 2018

\section{CURRENT MODEL}

\section{Ath}

In 2011, The Commission on Accreditation of

Athletic Training Education (CAATE) published the 5 th edition of the competencies required to be taught and evaluated in entry-level athletic training education." "Psychosocial Strategies and Referrals"l remains to be a stand-alone competency vital to the minimum education for athletic trainers. ${ }^{+}$Identification, referral, and support for patients with behavioral health conditions will also be included in the updated competencies that will apply in 2020 as minimum athletic training education advances to a Master's degree. ${ }^{2}$ Athletic trainers must have the ability to recognize when a patient is experiencing a social, emotional, or psychological concern. ${ }^{1,3}$ In addition to simple recognition, the Role Delineation Study, ${ }^{4}$ which guides practicing athletic trainers ${ }^{4}$, states that athletic trainers must understand the steps for intervention which includes emergency management, emergency action planning, and appropriate referrals. Although athletic trainers may currently be familiar with the impact of injury on mental health as it relates to athletic identity and participation, it may be even more important to understand underlying behavioral health conditions and when life events that are related; or unrelated; to athletic participation may trigger a more serious psychological concern. ${ }^{3}$

In the college and university setting, athletic trainers have resources from both the National Athletic Trainers Association (NATA), the National Collegiate Athletics Association (NCAA), and each individual institution regarding psychological concerns in this population. However, for athletic trainers in the secondary school setting, there may be limited resources. As most colleges and universities have student health centers and psychological services available for referral on campus, secondary school athletic trainers may be in a unique setting to require community resources and outside relationships to assist in management and referral of these patient cases. Athletic trainers in the secondary school setting need to have an understanding of the common conditions 
experienced by their patient population, and have site-specific policies and procedures reflective of best practices.

Site-specific policies and procedures outlining the available services and emergency action plans (EAP) is vital to any athletic training clinic to minimize organization and personal risk. ${ }^{4}$ The first step for athletic trainers is to establish the need for site-specific policies and prioritize the development of these policies based on patient needs. In review of the current policies and procedures manual at the target high school, there was a clear need for several new or updated policies. Within the needs assessment, we noted that a behavioral health policy was not currently included in the policy and procedure manual. As athletic trainers are bound by the practices set forth in position and consensus statements provided by the NATA, it was clear that our clinic could be legally vulnerable in a legal setting without procedures guiding the management of psychological concerns. Of the identified needs, the behavioral health policy then became our first priority. The purpose of the following document is to provide athletic trainers with a framework for the development and successful implementation of evidence-based policies and procedures to improve athletic training services at secondary schools. Using the process of developing a behavioral health policy for three high schools within a rural school system in Indiana as an example, the challenges and barriers to the implementation of new policies at a secondary school will be discussed.

\section{PDSA CYCLE}

Plan - Researching the topic for your chosen policy and procedure is important for the drafting of the document, as well as the advocacy and education that may be required for staff and stakeholders to buy-in to implementation. For the behavioral health policy, research was focused on epidemiology of mental health concerns in adolescents ${ }^{5,6}$, recommendations for best practices 3,7 , athletic trainers practice analysis ${ }^{4}$, and what athletic trainers already know about identifying psychosocial concerns. ${ }^{8}$ In the research phase, we also chose to reach out to school counselors as a key resource in the development of the policy. The school counselors provided us with specific

Copyright (C) by Indiana State University All rights reserved. ISSN Online 2577-8188 contact information for community behavioral health resources, contact information for appropriate school administration as well as current policies for management of behavioral health concerns during school hours. During school hours, teachers and other school personnel had direct access to guidance counselors as well as an established emergency response team. Although these individuals were not on campus during most athletic practices and events, it served as a framework for the hierarchy of communication within the school administration that we needed to implement when an incident did occur. After discussion with guidance counselors, we were also able to establish the best mechanism for follow-up of non-emergent concerns that could be addressed during the following school day, which was an important portion of our final document.

Table 1. Timeline for Implementation of Behavior Health Policy.

\begin{tabular}{ll}
\hline $\begin{array}{l}\text { Draft document } \\
\text { Review draft with supervisor } \\
\text { Schedule meeting with } \\
\text { outreach coordinator } \\
\text { Develop educational } \\
\text { materials } \\
\text { Schedule meeting with school } \\
\text { counselors }\end{array}$ & $\begin{array}{l}\text { January } 12 \\
\text { January 20 } \\
\text { January } 31\end{array}$ \\
$\begin{array}{l}\text { Schedule meeting with school } \\
\text { nurse }\end{array}$ & February 15 \\
$\begin{array}{l}\text { Schedule meeting with school } \\
\text { administration }\end{array}$ & February 20 25 \\
$\begin{array}{l}\text { Edit document with } \\
\text { stakeholder feedback } \\
\text { Submit for final approval } \\
\text { Disperse to each secondary } \\
\text { school } \\
\text { Discuss policy with staff and } \\
\text { students }\end{array}$ & March 1 \\
\hline
\end{tabular}

It is also important to consider each of the individual players that might be involved in the approval process of a new policy. Stakeholder buy-in is a common challenge encountered when attempting to implement change in any setting. The timeline for implementation included individual meetings with each stakeholder that would be impacted or included in the policy. Developing education materials such as handouts and Microsoft PowerPoint ${ }^{\circledR}$ presentation may be 
an effective way to communicate the importance of the change you are intending to implement at each of these stakeholder meeting. The individual meetings and discussions that were included in the process of implementing a behavioral health policy were integral to the successful approval by the school board (Table 1).

Do - The behavioral health policy was developed for a hospital-based athletic training outreach program that provided services to three area secondary schools. The purpose of the policy was to outline the referral and management processes for psychological concerns. The policies were highly reflective of the suggestions from the NATA Interassociation Recommendations for Developing a Plan to Recognize and Refer Student-Athletes with Psychological Concerns at the Secondary School Level: A Consensus Statement. ${ }^{3}$ Table 2 outlines the sections that were present in our policy and procedure document that were developed based on best-practice guidelines.

\begin{tabular}{ll}
\hline $\begin{array}{l}\text { Table 2. Sections of Behavioral Health Policy } \\
\text { \& Procedure Document. }\end{array}$ \\
\hline Policy & $\begin{array}{l}\text { Brief statement of guiding } \\
\text { principles }\end{array}$ \\
Recognition & $\begin{array}{l}\text { Depression, anxiety } \\
\text { disorders, substance and } \\
\text { alcohol abuse, ADHD, eating } \\
\text { disorders/disordered eating, } \\
\text { bullying, and hazing }\end{array}$ \\
Procedures & $\begin{array}{l}\text { Emergency referral, non- } \\
\text { emergent referral, bullying, } \\
\text { suspected child abuse, } \\
\text { documentation }\end{array}$ \\
Contacts & $\begin{array}{l}\text { School administration, school } \\
\text { counselors and nurses, } \\
\text { community emergency rooms, } \\
\text { community behavioral health } \\
\text { centers }\end{array}$ \\
\hline
\end{tabular}

When developing the document, keep the audience, most likely highly influential stakeholders, in mind. The final policy and Procedure (Appendix A), whereby the introduction included information to establish the need for the patient population as well as the

Copyright ( $)$ by Indiana State University All rights reserved. ISSN Online 2577-8188 policy. Especially for a topic such a psychosocial concerns, it was important to educate stakeholders on what the impact of these conditions are in secondary school settings, as well as the educational background and role that athletic trainers are prepared to play when such situations arise. ${ }^{4}$

When drafting a document, it is also important to remember that a policy is very different from procedures, and they should be easily identified as separate components of a document. A policy should be a short 2-3 sentence summary of the overall expectations or principles for the policy. A procedure on the other hand, are typically long, very descriptive, step-by-step instructions on how to achieve the policy. ${ }^{9}$ The following is an example of the behavioral health policy developed for these schools:

The athletic trainer is responsible for the recognition and referral of psychological concerns in studentathletes. The athletic training staff will differentiate between emergent and non-emergent concerns and refer to the school administration and appropriate medical professionals in all cases. The athletic training staff will report any concerns to the high school administration and parents/guardian for further case management.

Study - As in any setting, challenges to implementation of a new policy in the secondary school setting did occur. For this particular model of outreach athletic training services, a policy/procedure had to be developed that was broad enough to cover 3 different athletic training facilities. This document did not include any site-specific contact information or emergency action plan details. This model would then allow for the approval of an overarching behavioral health policy that would then require each individual clinic to develop an amendment to this document that included site-specific contact information and locations. The biggest challenge was the lack of accountability for individual clinics to develop site-specific policies and procedures. The response to a behavioral health incident may not be as effective without the requirement of this amendment from each individual clinic.

Another unexpected barrier was the inconsistency of hours that school nurses spent on- 
campus. The school district has a pool of school nurses that provide services during limited hours at several different locations depending on weekly needs. During initial drafting of this document, school nurses played important roles as potential healthcare providers to assist in response and follow-up care for emergency cases such as self-harm or physical violence towards others. However, after meeting with several stakeholders, we decided to edit the document to reflect minimal requirements of school nurses to respond or be involved in these patient cases. Although the model for secondary school services will be different at each site, it is important for athletic trainers to know the resources available to them on-campus and within the community, and develop policies and procedures dependent on these resources.

An additional barrier during implementation was the sharing of medical information related to a patient. The Health Insurance Portability and Accountability Act (HIPAA) and the Family Education Rights and Privacy Act (FERPA) place strict and important guidelines for the protection of personal health information of minors. ${ }^{10}$ In the development of the behavioral health procedures, school counselors were a required call after an emergent situation, as well as a resource for athletic trainers in non-emergent cases. Upon review of the confidentiality waiver located in athlete's pre-participation evaluation, it appeared that school counselors were not specifically listed as individuals in which health information may be shared. To avoid any potential legal complications for sharing medical or personal information between athletic trainers and school counselors, the form was modified to specifically list school guidance counselors. This will hopefully ensure that each patient and parent will be agreeing to the collaboration of these individuals in patient care.

Act - For clinicians in any athletic training setting, it is important to review your current policy and procedure manual to determine where improvements can be made. Policy and procedure manuals are meant to guide clinical practice at your site, and include details about any services you may provide. These documents help ensure your patients are being provided the best possible care, but they also help protect you legally. Although the current project remains in

Copyright ( $)$ by Indiana State University All rights reserved. ISSN Online 2577-8188 the "study" phase, the information gathered will need to be used to enhance and continually evolve this policy. School administrators and athletic trainers should conduct an end-of-year review to discuss modifications and improvements to the policy. The efficiency of emergency response, timeliness of communications and referrals, as well as patient outcomes may be areas worth evaluating.

\section{CLINICAL BOTTOM LINE}

The first step to in improving your policies is to establish the need. This step may include researching NATA position and consensus statements to evaluate how your current practices compare to best practice guidelines. During development of policies and procedures, it is important to meet and discuss procedures with each stakeholder who may be involved and impacted after implementation. After approval from the needed stakeholders, it is also important to remember that the process is not yet complete. Staff education and evaluation of policy and procedure implementation success is a continuous process. Although barriers will undoubtedly arise during the development and implementation process, improving policies and procedure manuals for athletic training services in the secondary school setting is possible with a clear plan and the inclusion of stakeholders throughout the process to improve buy-in.

\section{REFERENCES}

1. National Athletic Trainers Association. The Athletic Trainer Educational Competencies. 5th Edition. The Comission on Accredidation of Athletic Training Education, Austin TX. 2011. Accessed January 2017.

2. CAATE 2020 Standards for Accreditation of Professional Athletic Training Programs. Comission on Accreditation of Athletic Training Education Website. https://caate.net/new-standards-releasefor-professional-masters-level-athletictraining-programs/. Accessed May 2018.

3. Neal TL, Diamond AB, Goldman S, et al. Interassociation recommendations for developing a plan to recognize and refer student-athletes with psychological concerns at the secondary school level: A consensus statement. J Athl Train. 2015;50(3):231-249. 
https://doi.org/10.4085/1062-6050$\underline{50.3 .03}$

4. Henderson, J. The 2015 Athletic Trainer Practice Analysis Study. Omaha, NE: Board of Certification; 2015. Accessed January 2017.

5. Mental Health Information. National Institute of Mental Health Website.

www.nimh.nih.gov/health/topics/index.shtml. Accessed January 2017.

6. Substance Abuse and Mental Health Services Administration, Results from the 2013 National Survey on Drug Use and Health: Mental Health Findings. NSDUH Series H-49, HHSPublication No. (SMA) 14-4887.

7. Rockville, MD: Substance Abuse and Mental Health Services Administration, 2014.

8. Bonci $C M$, Bonci $L J$, Granger LR, et al. National athletic trainers' association position statement: Preventing, detecting, and managing disordered eating in athletes. $J$ Athl Train. 2008;43(1):80-108. https://doi.org/10.4085/1062-605043.1.80

9. Cormier ML, Zizzi SJ. Athletic trainers' skills in identifying and managing athletes experiencing psychological distress. J Athl Train. 2015;50(1 2):1 267-1276. https://doi.org/10.4085/1062-605050.12.02

10. Ray R, Konin JG. Management Strategies in Athletic Training. $4^{\text {th }}$ Edition. Champaign, IL: Human Kinetics; 2011.

11. Department of Education. Joint Guidance on the Application of the Family Educational Rights and Privacy Act (FERPA) and the Health Insurance Portability Act of 1996 (HIPAA) To Student Health Records. 2008. https://www2.ed.gov/policy/gen/guid/fpc $\circ /$ doc/ferpa-hipaa-guidance.pdf. Accessed January 2017. 


\section{APPENDIX A - PSYCHOLOGICAL CONCERN: RECOGNITION AND REFERRAL POLICY}

\section{INTRODUCTION}

The rate of mental disorders in youth is high, with approximately 1 in every 4-5 meeting the criteria. ${ }^{1}$ Athletic trainers in the secondary school setting may play a vital role in identifying and referring patients with psychological concerns. Adolescent athletes are exposed to the same stressors that place them at-risk for new or worsening mental disorders as other adolescents; however, performance expectations, time-loss, career ending injuries, team conflict, and other sports-related pressure may cause additional strain. ${ }^{1}$ Although approaching patients regarding mental health may be uncomfortable or new for athletic trainers, we may have unique relationships with our patients that allow them to confide, seek help, or speak openly in our presence. The secondary school athletic trainer must be prepared to recognize, respond, refer and advocate for a patient's mental health appropriately.

This policy was developed for a hospital-based athletic training outreach program with the purpose of outlining the referral and management process of psychological concerns. The policies outlined below were highly reflective of the suggestions from the National Athletic Trainers' Association (NATA) Interassociation Recommendations for Developing a Plan to Recognize and Refer Student-Athletes with Psychological Concerns at the Secondary School Level: A Consensus Statement, 1 and athletic trainers should familiarize themselves with this resource. This consensus statement, as well as an NATA position statement regarding mental health, can be found on the NATA website.

\section{POLICY}

The athletic trainer is responsible for the recognition and referral of psychological concerns in studentathletes. The athletic training staff will differentiate between emergent and non-emergent concerns and refer to the school administration and appropriate medical professionals in all cases. The athletic training staff will report any concerns to the high school administration and parents/guardian for further case management.

\section{Recognition}

Distinguishing an emergent versus a non-emergent case is crucial in the management of psychological concerns in athletes and is outlined in the consensus statement as well as later in this policy. As athletic trainers we interact with our patients often daily, and build close relationships. Triggering events in life or sport can cause the worsening or development of a psychological concern. It is important for athletic trainers to be empathetic and recognize when these triggering events may have occurred to better monitor the patient's status. Triggering events specific to athletes may be overtraining, termination of sport participation, inability to manage sport, academic, and personal expectations, injury, as well as any changes in home or social environments. Athletic trainers may see these events begin to affect motivation, pain levels, injury occurrence, attention, mood, or behavior. Although there does not always need to be a specific triggering event prior to development or worsening of a mental disorder, athletic trainers need to recognize these changes as they are some of the primary signs of mental disorders. The primary mental disorders discussed in the NATA consensus statement include:

- Depression

- Anxiety Disorders

- Substance and Alcohol Abuse

- ADHD

- Eating Disorders 
- Bullying and Hazing.

Athletic trainers should read this consensus statement and understand the signs and symptoms of each. Detailing each disorder is beyond the scope of this policy, but athletic trainers should attest to having read and understood this document, as well as the consensus statement, prior to patient contact.

\section{Suicide}

Any student-athlete who has expressed intent, indicated a plan, or has attempted or discussed attempted suicide, should be treated as an emergency referral. Athletic trainers should not engage in an attempt to determine the seriousness of the expressed thoughts. Stay with the patient, listen, and make an immediate referral.

- If an attempt is in progress: Call EMS.

- If an attempt has not already begun: Call the school counselor and/or school administrator. Parent/guardian will also be notified immediately. If these individuals are not available to respond, call the "insert community resource name."

\section{PROCEDURES}

As stated in NATA Interassociation Recommendations for Developing a Plan to Recognize and Refer StudentAthletes with Psychological Concerns at the Secondary School Level: A Consensus Statement, a "Yes" to ANY of the following questions should constitute an emergency:

0 Am I concerned the student-athlete may harm himself/herself?

o Am I concerned the student-athlete may harm others?

0 Am I concerned the student-athlete is being harmed by someone else?

o Did the student-athlete make verbal or physical threats?

0 Is the student-athlete exhibiting unusual ideation or thought disturbance that may or may not be due to substance use?

o Does the student-athlete have access to a weapon?

0 Is there potential for danger or harm in the future?

Any threat or perceived suicide attempt, changes in mental status or destructive behaviors constitutes an emergency under any circumstances and EMS should be activated.

In the case of a "yes," school administration (principal/athletic director and school counselor) should be immediately notified. If administration is currently not on-site, they should still be notified about the incident as soon as reasonably possible. If possible, one athletic trainer will continue to monitor and manage the patient, while another athletic trainers call administration, parents, and/or referral. If a second athletic trainer is not available, a school administrator can be used to contact parents. The responding school administrator will also be responsible for activating EMS if needed.

If possible, the athletic trainer should always defer the incident to a school counselor, administrator, or the school nurse or health assistant. As a school nurse is not always on campus, athletic trainers should report to the guidance counselor first. Once a non-emergent situation is deferred to a school administrator, the athletic trainer can be relieved of immediate responsibility and return to other duties.

Bullying: The school corporation has a no-tolerance policy for bullying of any kind. Bullying can include physical, sexual, or emotional abuse. If the athletic trainer witnesses or suspects bullying, this includes hearing student-athletes discussing previous events, they are to report to the school administration or school guidance counselors immediately. The athletic trainer will intervene in the case of active bullying.

Child Abuse: SUSPICION alone mandates and justifies action by a healthcare provider. Athletic trainers will make a direct report to Department of Children's services or a law enforcement agency. However, athletic 
trainers will report that a call was made to appropriate school administrators and the sports medicine director.

- Child Protective Services: 1-800-800-5556

\section{Emergent Referral Process}

Listed below are the options for referral or resources in the case of an emergency.

1. List local behavioral health organizations \& contact information

2. List local emergency rooms \& contact information

3. National Suicide Prevention Lifeline: 1-800-273-TALK (8255)

4. Child abuse/neglect hotline: 1-800-800-5556

\section{Non-Emergent Referral Process}

Student-athletes must be referred to the school counselor prior to non-emergent referral to the local behavioral health clinic. Our school corporation has a working relationship with this clinic and the proper forms required for referral are available from a school guidance counselor and attached to this document.

Notify parents, school administration, and counselors.

\section{Documentation}

After any of the above incidents, multiple levels of documentation are required within 48 hours of the incident.

1. "Incident Report" form- This form is available from the athletic office. Upon completion, follow instructions on the form to distribute to the Athletic Director or appropriate administrator.

a. This form can be saved on the computer, but needs to be password protected.

2. Sportsware (Medical Records System)-Document this incident in the "Notes" tab under the "athletes" tab. No specific injury needs to be created unless relevant. This documentation needs to at least include:
a. Date
b. Time
c. Observations
d. Summary of patient encounter
e. Who was contacted and when
f. Referral
g. Plan of care/follow-up.

3. Following a mental health referral, a note from the treating healthcare provider should be obtained prior to return to activity.

\section{Legal Considerations}

In the case of self-harm, or harm to others, patients and parents should be aware that patient and personal information will be shared among appropriate personnel. This is addressed in the medical release form of the pre-participation physical packet.

\section{Contact Information}

Each individual school should compile a contact list and working relationships with the following personnel to effectively execute these policies and procedures:

- Principal 
- Assistant Principal

- Athletic Directors

- Assistant Athletic Directors

- School Nurse/Nurses and health assistants

- School Counselors

- Local behavioral health centers and hospitals.

\section{SOURCES OF ADDITIONAL INFORMATION}

- Emergency Action Plan Guidelines: Mental Health Emergency Secondary School Athletes https://www.nata.org/sites/default/files/mental health eap guidelines.pdf

- Interassociation Recommendations for Developing a Plan to Recognize and Refer Student Athletes with Psychological Concerns at the Secondary School Level: A Consensus Statement

- Indiana State Suicide Prevention Plan: http://www.in.gov/issp/files/plan.pdf

- Indiana State Statutes: https://www.childwelfare.gov/topics/systemwide/lawspolicies/state/?CWIGFunctionsaction=statestatutes:main.getResults

- Suicide prevention organizations in Indiana (contacts) http://www.in.gov/isdh/25392.htm

\section{REFERENCE}

1. Neal TL, Diamond AB, Goldman S, et al. Interassociation recommendations for developing a plan to recognize and refer student-athletes with psychological concerns at the secondary school level: A consensus statement. J Athl Train. 2015;50(3):231-249. 